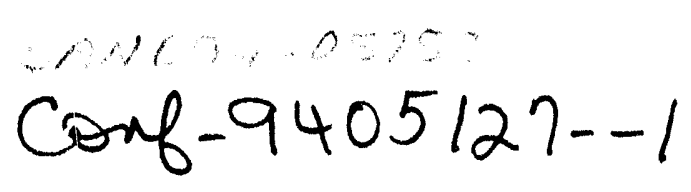

\title{
Network Analyzer Calibration for Cryogenic On-Wafer Measurements
}

\author{
Vincent M. Hietala, Mark S. Housel, and Robert B. Caldwell \\ Sandia National Laboratories \\ Albuquerque, New Mexico 87185-0603
}

\begin{abstract}
A cryogenic probe station for on-wafer microwave measurements has been developed at Sandia National Laboratories to explore basic device physics and characterize advanced components for low-temperature applications. The station was designed to operate over a temperature range of 20 to $300 \mathrm{~K}$ with a frequency range of $\mathrm{DC}$ to $50 \mathrm{GHz}$. Due to the vacuum and the low temperature environment, the use of microwave probes and the calibration of network analyzer measurements are somewhat elaborate. This paper presents guidelines for probe use and calibration in this environment.
\end{abstract}

\section{Introduction}

Interests in advanced component development at Sandia include both compound semiconductor and high-temperature superconducting devices. Measurements on these types of advanced electronic components at cryogenic temperatures can be a significant aid to understanding device physics. Furthermore, there are applications that inherently require device characterization at cryogenic temperatures such as space-based systems. For these reasons, the addition of a cryogenic microwave probe station considerably enhances the range and flexibility of our characterization capabilities.

Several other systems exist for on-wafer cryogenic probing which have been used to measure several active semiconductor and superconductive devices [1-4]. The system described here features a closed cycle helium cryostat alloying for prolonged cryogenic operation and electric motors located within the vacuum chamber providing for probe manipulation over a 2 " travel.

In this paper, a brief discussion on probe station design issues related to on-wafer calibration and microwave probe use is presented. This is followed by discussions specific to network analyzer calibration. Finally, measured data from a test transistor is presented to illustrate measurement quality.

\section{Probe Station Design}

The design of this probe station addresses many technical challenges imposed by the hostile experimental conditions. Since operation below liquid nitrogen temperature is required, a conventional dry box approach is not possible. Instead, an approach that incorporates the probes, positioning motors, stages, and sample within a 30" diameter custom vacuum chamber is used. To implement this approach several problems associated with realizing high-frequency vacuum probing had to be solved. For instance, reliable probe contact requires a significant degree of vacuum pump and cryo-cooler vibration isolation. In addition, a reliable method for the precise

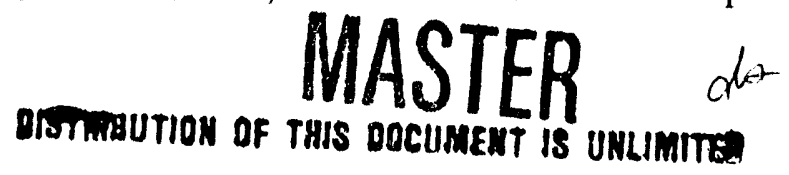




\section{DISCLAIMER}

This report was prepared as an account of work sponsored by an agency of the United States Government. Neither the United States Government nor any agency thereof, nor any of their employees, makes any warranty, express or implied, or assumes any legal liability or responsibility for the accuracy, completeness, or usefulness of any information, apparatus, product, or process disclosed, or represents that its use would not infringe privately owned rights. Reference herein to any specific commercial product, process, or service by trade name, trademark, manufacturer, or otherwise does not necessarily constitute or imply its endorsement, recommendation, or favoring by the United States Government or any agency thereof. The views and opinions of authors expressed herein do not necessarily state or reflect those of the United States Government or any agency thereof. 
placement of the delicate microwave probes must be found. Even items as simple as $50 \mathrm{GHz}$ vacuum feed throughs posed difficulties in system integration.

A closed-cycle Helium refrigerator provides continuous operation for indefinite periods of time. This cooling method is well suited for time-consuming microwave measurements and can maintain stable cryogenic temperatures over extended time scales. A two-stage CTI model 1050 refrigerator was used for cooling. The first stage achieves a temperature in the $60 \mathrm{~K}$ range with several 10's of Watts heat load. The second stage achieves a temperature of approximately $12 \mathrm{~K}$ with a $1 \mathrm{~W}$ heat load. To obtain low sample temperatures, a novel heat shield arrangement is used allowing for $2 "$ of probe travel while maintaining complete thermal shielding of the sample. This is achieved with moveable heat shields attached to the arms holding the sample probes. The heatshield is coupled directly to the first stage. The sample stage is thermally connected directly to the second stage.

Figure 1 shows a photograph of the overall system. A turbo molecular pump is used to provide the vacuum required at cryogenic temperatures. Visual access of the chamber is achieved through a view port on the top of the chamber. A long-working-distance microscope (Infinity Photo-optic's K2) is used for both direct visual and video camera access of the sample area. This provides the range of magnification crucial for accurate probe placement. The probes are positioned using DC servo motor driven stages (Newport/Klinger) located within the vacuum chamber. To help protect the delicate microwave probes, the motors have $1 \mu \mathrm{m}$ linear encoders and probe positions are monitored by computer to avoid collisions.

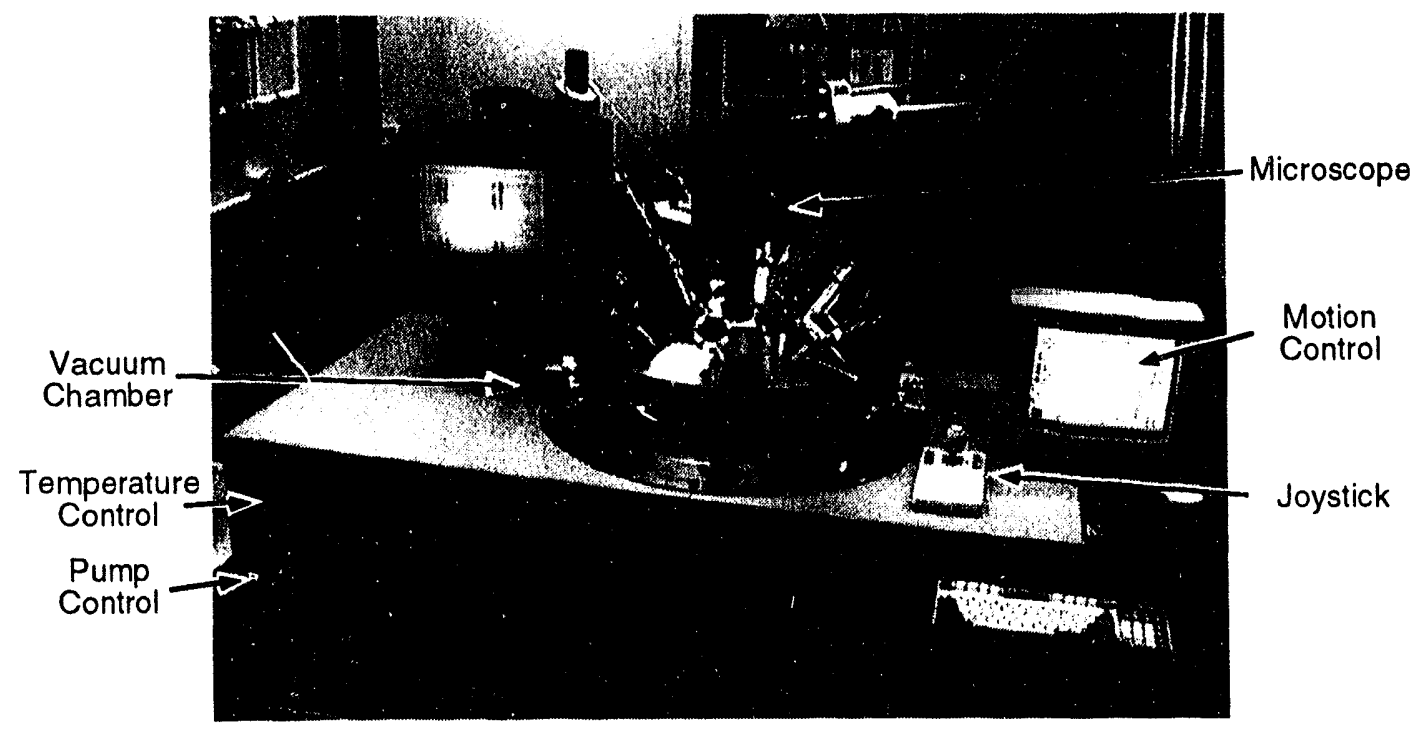

Figure 1. The cryogenic probe station is based on a $30^{\prime \prime}$ vacuum chamber. The computer on the right assists in probe placement. The monitor on the left provides a view into the chamber.

The top of the vacuum chamber is designed to be lifted by a hoist and rotated to the side of the system allowing access into the chamber as shown in Figure 2. The sample is located on a vibration isolated stage at the center of the vacuum chamber as shown in Figure 3. Cascade Microtech microwave probes are used to make contact to the device. The probes are thermally connected to the heat shield system resulting in a probe temperature around $100 \mathrm{~K}$. At higher sample temperatures, the probe temperature is close to the sample's. In either case, coupling the 
probes to the heatshield helps minimize the thermal load to the sample stage during probe contact.

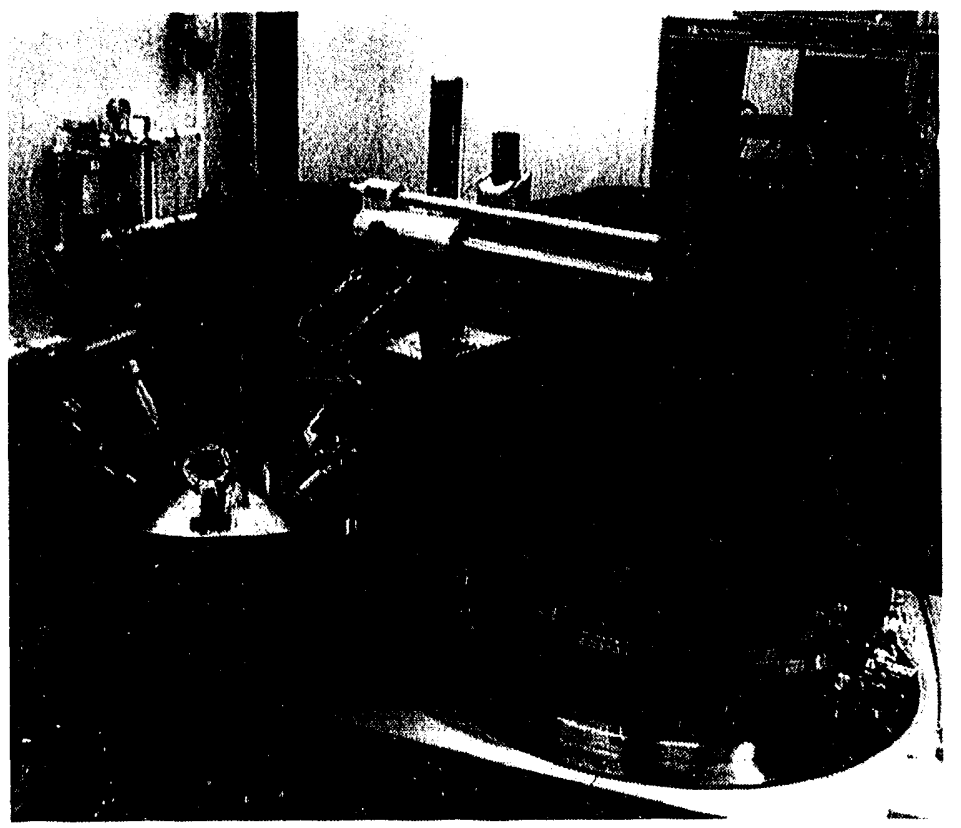

Figure 2. Cryogenic probe station with top open. The top of the vacuum chamber and microscope system are lifted by an electric hoist and pivoted clear for chamber access.

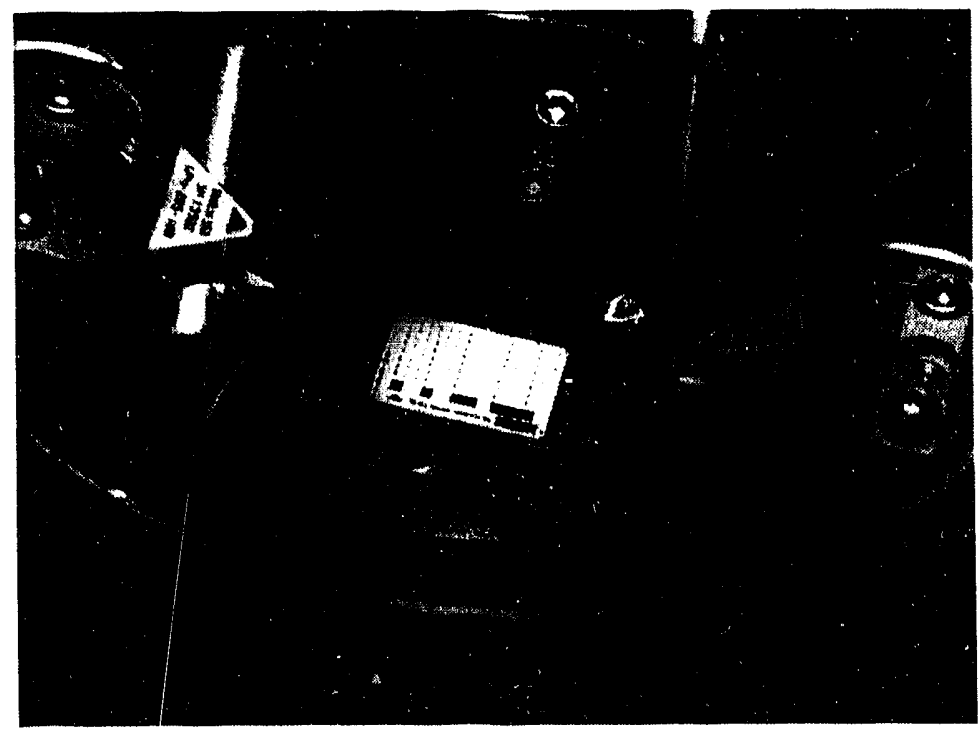

Figure 3. Close-up of sam le stage inside the chamber. The cylinder around the edge of the photo is part of the heat shield system. During normal operation, a lid with a quartz window is attached as part of the thermal shielding.

Figure 4 shows a plot of system temperatures during a cool-down and warm-up cycle. At $\mathrm{t}=0$ the refrigerator was started. After approximately $240 \mathrm{~min}$. (4 hours) the refrigerator was turned off. From this graph, it is apparent that sample temperatures down to $50 \mathrm{~K}$ can be 
achieved very quickly (within 1 hour); whereas obtaining the lower temperature extremes may take several hours. Also note that the system warms up slowly over several hours which is necessary to achieve good thermal stability during cryogenic operation. Temperature control is achieved by using two resistive heaters. A 25 Watt wire heater is wrapped around the sample stage and is controlled by a commercial temperature controller. A second $75 \mathrm{~W}$ att heater is attached to the first stage and can be used to provide a boost in heating power.

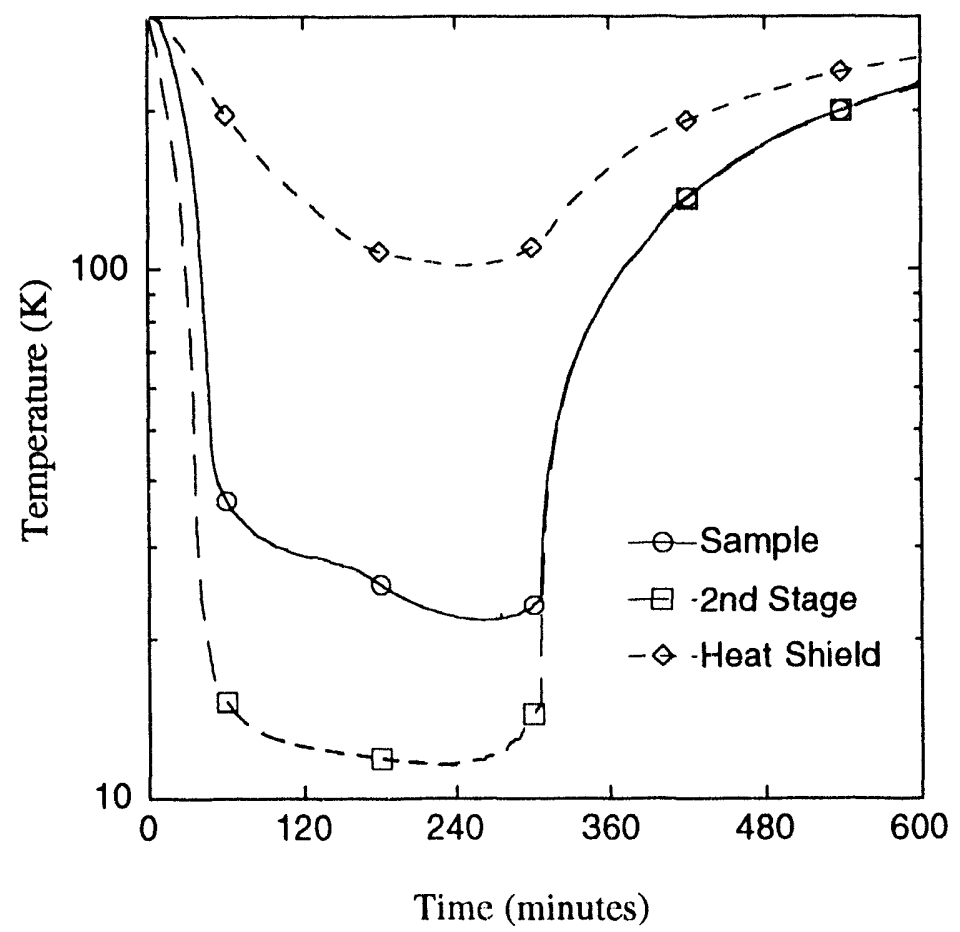

Figure 4. Temperature during a system thermal cycle. Depending on target temperature thermal equilibrium can be achieved in several hours.

\section{VNA Calibration}

Network analyzer calibration for the probe station is an interesting and somewhat difficult task. In spite of efforts to simplify the probing operation, it is still time consuming to perform calibrations. Therefore, effort in selecting the best possible calibration technique and in resolving temperature dependencies is important. Since resistive terminations are temperature dependent, it was first expected that Line-Reflect-Reflect-Match (LRRM), Line-Reflect-Match (LRM), or Short-Open-Load-Thru (SOLT) methods of calibration would be problematic. Instead, a Thru-Reflect-Match (TRL) calibration was expected to be more suitable. This is particularly true in light of recent work on TRL calibrations at NIST.[5,6] However as seen below, the temperature dependence of the load resistor appears to be manageable so that the LRRM technique with load inductance compensation may be a desirable method of calibration due to its convenience. [7,8]

Measurements where performed using an 8510C with an 8715A testset. LRM and LRRM calibrations were performed with Cascade's VNA Calibration Software using Cascade's ISS. All 
LRRM calibrations used load inductance compensation. The TRL calibration was performed manually on the $8510 \mathrm{C}$ using the $10 \mathrm{ps}$ and $25 \mathrm{ps}$ transmission line sections on the ISS. All measurements used a VNA averaging number of 100 in step sweep mode. All cables used in the system are flexible Gore assemblies with $2.4 \mathrm{~mm}$ connectors. Custom $2.4 \mathrm{~mm}$ RF vacuum feed throughs with less than $0.5 \mathrm{~dB}$ loss at $50 \mathrm{GHz}$ provide electrical access into the chamber. Cascade's WPH-200 series ceramic tip GSG probes with $150 \mu \mathrm{m}$ pitch were used in all experiments presented here.

In spite of efforts to provide for efficient probe manipulation, probe positioning is not as convenient in our system as compared with room-temperature stations. We have also found that microwave probes cause significantly more damage to test devices and calibration samples when probing is performed under a vacuum. We are uncertain to the cause of this damage. We know it is not related to a lack of probe motion control. If the alignment guides on the Cascade ISS are faithfully used, ISS calibration standards are good for only one probe contact! Reduced overtravel amounts are necessary for non-destructive testing when probing. In short, it is very desirable to minimize the number of contacts required during a calibration and measurement.

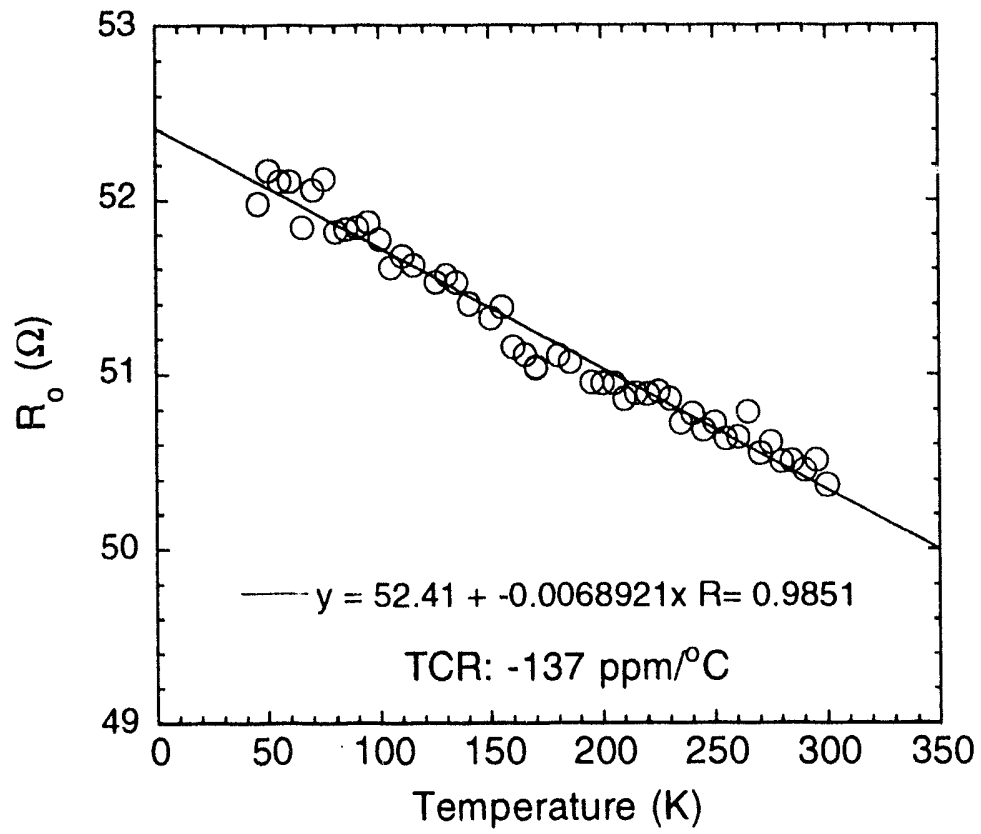

Figure 5. Measured temperature dependence of Cascade's ISS "50 $\Omega$ load".

In order to utilize any calibration technique requiring a load, the load temperature dependence must be understood. Figure 5 shows the measured temperature dependence of a $50 \Omega$ load on the Cascade ISS. This data was measured point by point by placing a microwave probe on the resistor at each temperature. The background resistance (i.e. cables and probes) is compensated for in Figure 5 by subtracting the measured resistance with the probes shorted at each temperature. The resulting data in Figure 5 indicate an approximately linear temperature dependence $\left(\approx-137 \mathrm{ppm} /{ }^{\circ} \mathrm{C}\right.$ ) over the entire measurement range of 45 to $300 \mathrm{~K}$. This corresponds quite well with Cascade's quoted value of $-125 \mathrm{ppm} /{ }^{\circ} \mathrm{C}$. For the particular resistor randomly selected for this test, the room temperature $(T \approx 300 \mathrm{~K})$ value is slightly greater than 
$50 \Omega$ 's, but the normalized temperature dependence should be valid. The temperature dependent deviation from $50 \Omega$ 's is small and can be easily accounted for in a calibration.

As a consistency test, calibration was performed using the TRL technique and measurements of the $50 \Omega$ loads were performed at $70 \mathrm{~K}$. Measurements of the $50 \Omega$ loads resulted in an extrapolated DC resistance value of about $48.5 \Omega$. From Figure 5 the expected value is approximately $51.9 \Omega$. This is not a particularly large difference for most applications, but it is statistically significant. This inconsistency is probably due to a deviation of the characteristic impedance of the delay lines from $50 \Omega$ 's at $70 \mathrm{~K}$.

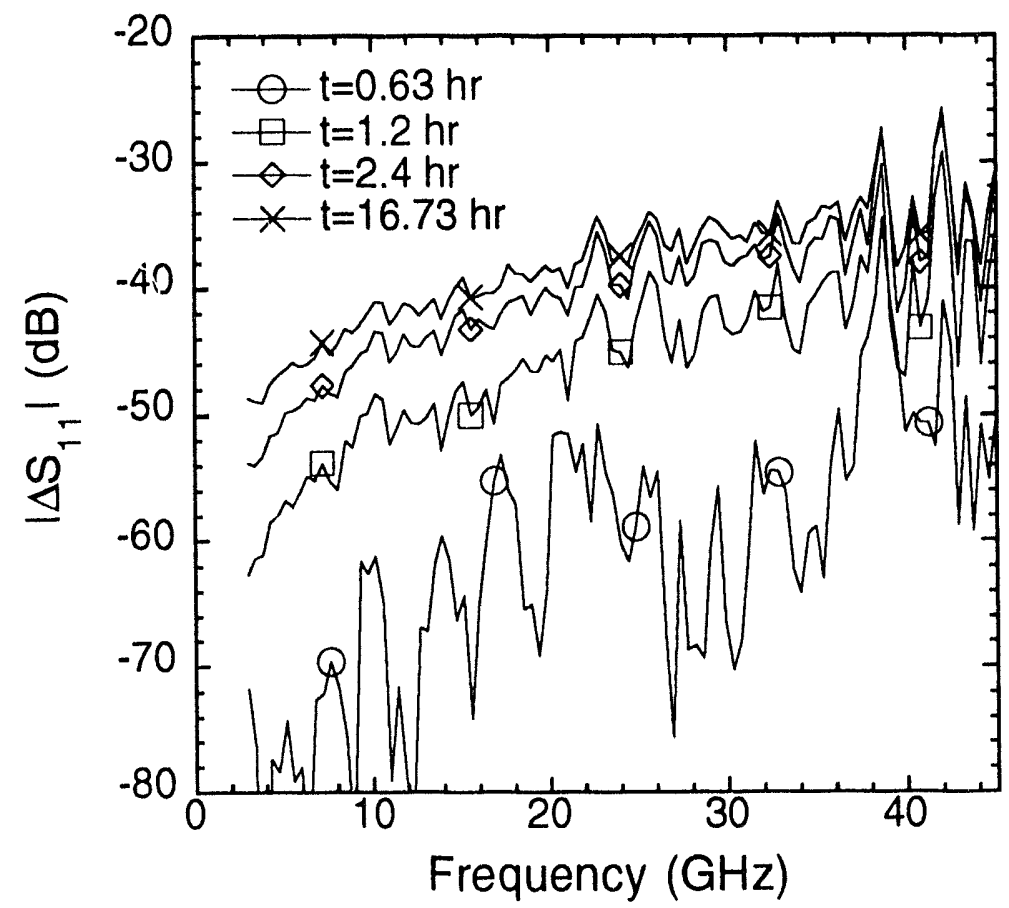

Figure 6. Measured time dependence of an open probe based on a TRL calibration $\left(\mathrm{T}_{\mathrm{S}}=70 \mathrm{~K}\right)$.

Any calibration technique requires that the system be stable with time. To test system stability, a TRL calibration was performed and $S_{11}$ was measured over a period of time to observe the drift of system error terms. Figure 6 summarizes the results of this measurement which was performed at $70 \mathrm{~K}$. Significant drift was not observed until an hour after calibration. This drift was probably attributed to the long temperature equilibrium times within the system. Before the measurement, the system was held at $70 \mathrm{~K}$ for at least 6 hours. Note that even after 16 hours calibration is still adequate to $20 \mathrm{GHz}$ for many applications.

Since it is desirable to make measurements over a range in temperature, it is important to understand the RF temperature dependence of the system. Figure 7 shows a normalized plot of measured phase and magnitude as a function of heat shield temperature. The temperature dependence of $\left|S_{11}\right|$ and phase of $S_{11}$ was measured by placing the probes approximately $1 \mathrm{~mm}$ above the sample surface and allowing the system to reach thermal equilibrium over a period of several days $\left(\mathrm{T}_{\mathrm{S}} \approx 28 \mathrm{~K}\right)$. The refrigerator was then turned off and the system allowed to warm 
to room temperature. Heat shield temperature was measured and vector reflection data was gathered at port 1. An operating frequency of $50 \mathrm{GHz}$ was selected to provide good measurement sensitivity. The resulting data set shown in Figure 7 was collected over a 7 hour period and is normalized to unity at the low temperature extreme.

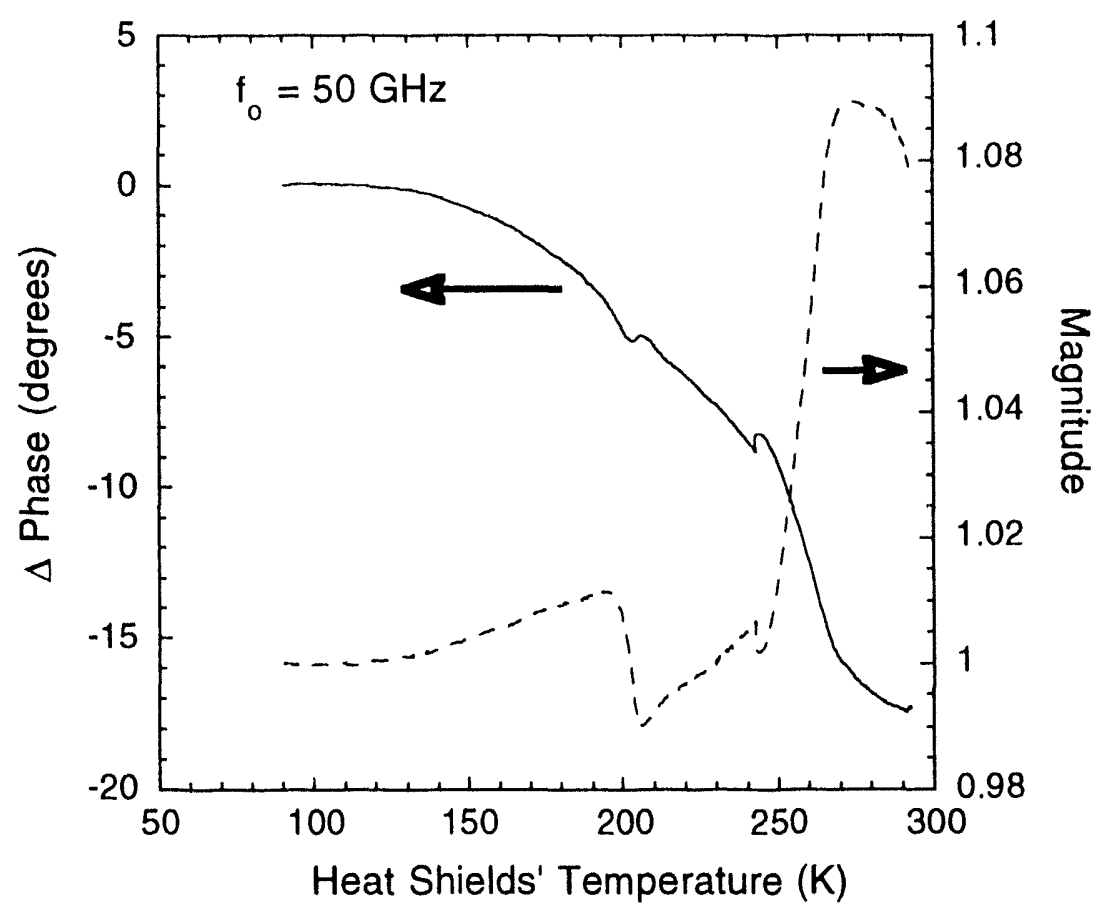

Figure 7. Temperature dependence of normalized $\left|S_{11}\right|$ and phase of $S_{11}$ of an open probe placed approximately $1 \mathrm{~mm}$ above the sample stage.

Interestingly, the phase shift variation is less than $18^{\circ}$ and the magnitude variation is less than $10 \%$ over the entire measurement range. In general, this reflection change is quite good especially considering the temperature range involved. Though this result indicates that calibrations performed at any given temperature will have some value at another temperature, it does not allow for a single calibration accurately covering the entire temperature range. One must calibrate over the temperature range of interest to achieve the best accuracy.

Another interesting observation from probing in a vacuum is the effect of residual gases on cable phase shift. At room temperature, starting from ? good vacuum $\left(1.6 \times 10^{-6}\right.$ torr) and venting the system to a dry $\left(-100\right.$ o $\mathrm{F}$ dew point) nitrogen atmosphere results in a $-5.4^{\circ}$ phase shift and $8.7 \%$ magnitude increase at $50 \mathrm{GH} z$. This phase change is attributed to the effect of nitrogen (or air) being incorporated into the voids of the insulation of the Gore cable assemblies. Therefore, the calibration pressure should be the same as the measurement pressure. In our system, a good vacuum $\left(1 \times 10^{-6}\right.$ to $1 \times 10^{-8}$ torr $)$ is always maintained at any measurement temperature. 

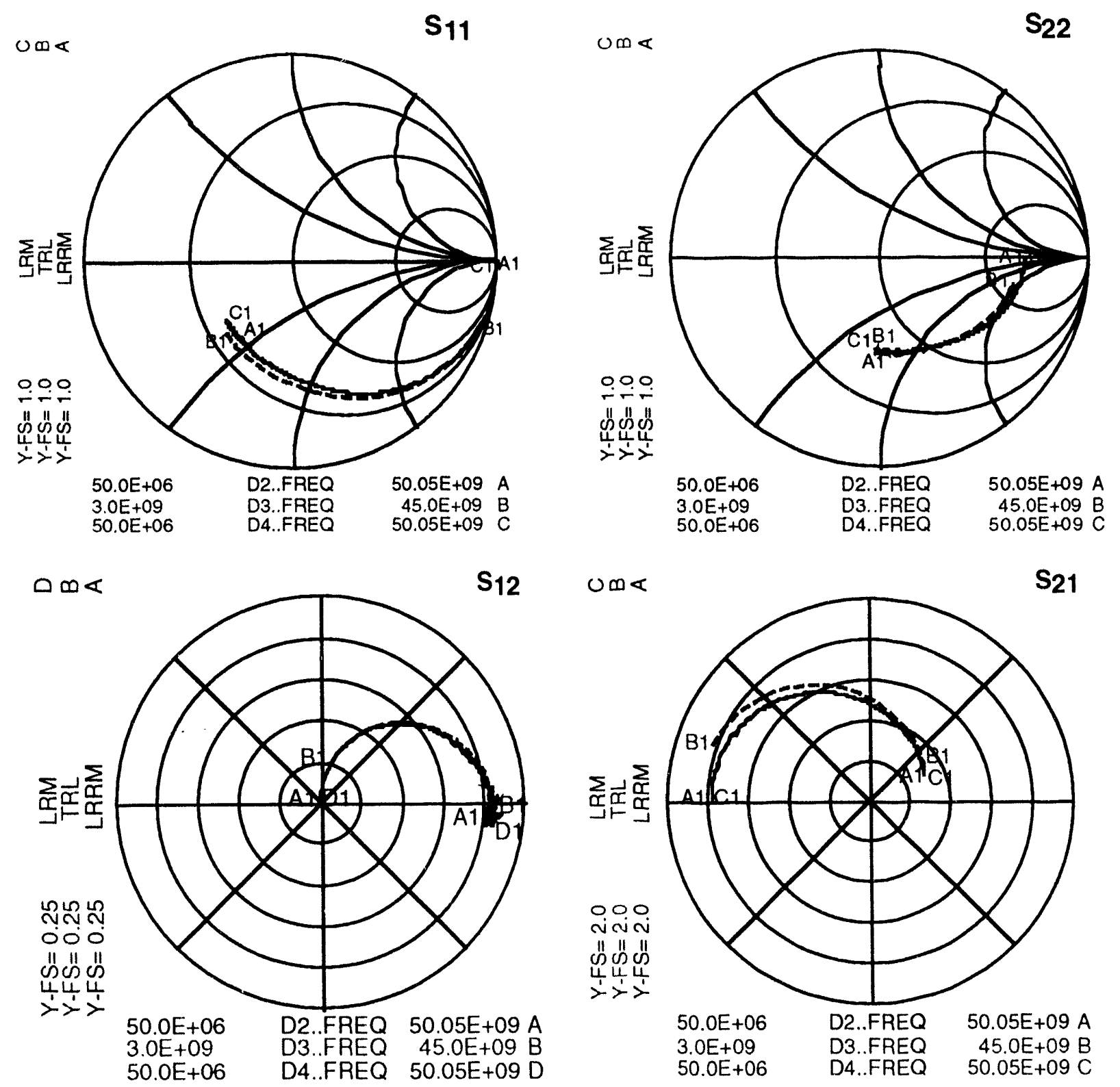

Figure 9. Measured S-parameters of a GaAs n-channel JFET at $70 \mathrm{~K}$ with LRM (open-load), TRL, and LRRM (w/ load inductance compensation) calibrations $\left(\mathrm{V}_{\mathrm{ds}}=1.5 \mathrm{~V}, \mathrm{~V}_{\mathrm{g}}=0.25 \mathrm{~V}\right)$. The measurements with LRM and LRRM calibration are virtually identical and shown by the solid lines. The measurement using TRL calibration is shown with dashed lines.

\section{Sample Measurement}

As a test case, an n-channel GaAs JFET structure was measured from 0.05 to $50 \mathrm{GH} \%$ at $70 \mathrm{~K}$. This JFET is being investigated for use in a low power GaAs complementary logic family. 
The device is fabricated by ion implantation with a self-aligned $\mathrm{Zn}$-gate approximately $0.8 \mu \mathrm{m}$ in length. Additional device details can be found elsewhere.[9]

Figure 9 shows measured $S$-parameters for this FET at $70 \mathrm{~K}$ with a bias of $\mathrm{V}_{\mathrm{ds}}=1.5 \mathrm{~V}$, $\mathrm{V}_{\mathrm{g}}=0.25 \mathrm{~V}$, and $\mathrm{I}_{\mathrm{d}}=17.2 \mathrm{~mA}$. Note that the measured S-parameters are smooth over the entire measurement range of $0.05-50.05 \mathrm{GHz}$. This characteristic indicates repeatable probe contact and good system stability. Interestingly, the TRL calibration differs significantly from the other calibration approaches. This difference is most likely due to a different reference impedance between the TRL calibrations lines (assumed to be $50 \Omega$ ) and the $50 \Omega$ lumped loads used for the other calibration techniques. To see the significance of this discrepancy, a plot of measured unilateral transducer power gain is shown in Figure 10. As seen in Figure 10, the different calibration techniques have little impact on this measurement or the popular transistor figure-of-merit $f_{\max }$.

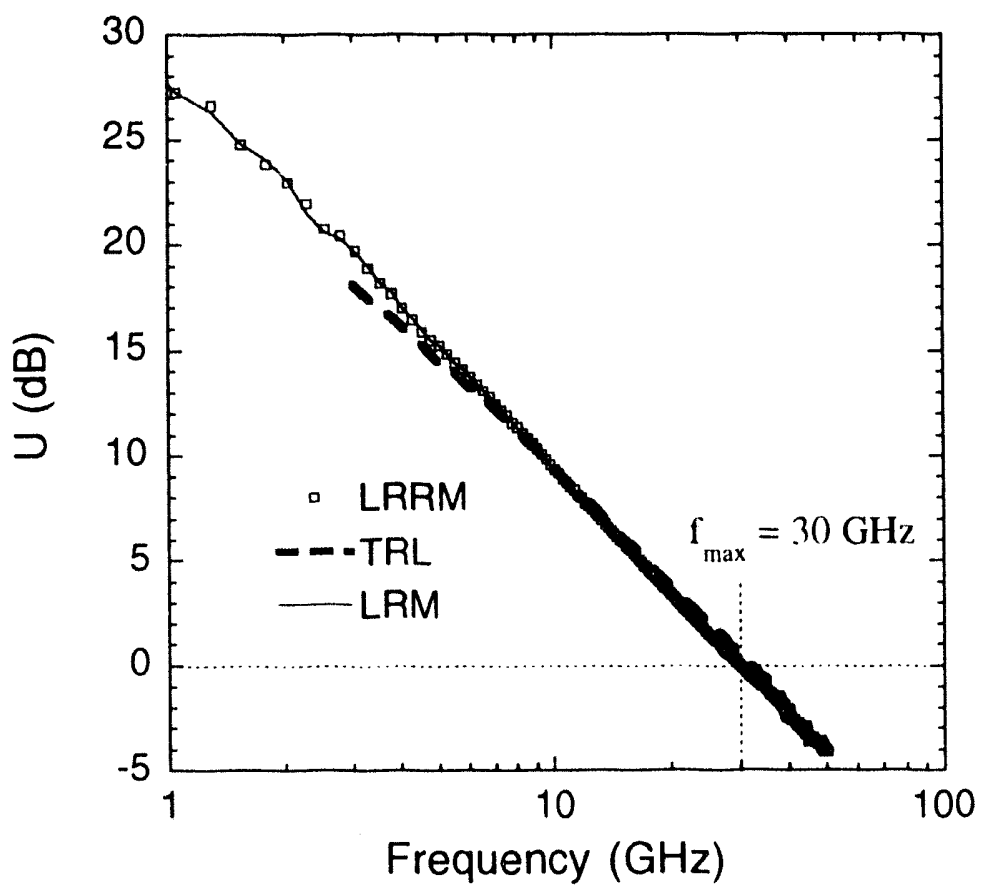

Figure 10. Measured unilateral transducer power gain (U) of an $n$ channel JFET at $70 \mathrm{~K}$ using the LRRM (w/ load inductance compensation), TRL, and LRM (open-load) calibrations ( $\mathrm{V}_{\mathrm{ds}}=$ $1.5 \mathrm{~V}, \mathrm{~V}_{\mathrm{g}}=0.25 \mathrm{~V}$, and $\left.\mathrm{I}_{\mathrm{d}}=17.2 \mathrm{~mA}\right)$.

\section{Conclusions}

Calibration techniques used for more usual room-temperature measurements appear adequate for cryogenic on-wafer measurements provided that corrections for temperature dependencies of the calibration standards are made. Data was presented on the temperature dependence of the load on Cascade's ISS substrate. Good temperature control, cooling of the probe heads, and low vacuum pressures all contribute to good system stability. In addition, waiting for system thermal 
equilibrium (several hour time scale) enhances measurement accuracy. As with room temperature measurements, prohe placement is important at cryogenic temperatures for accurate reproducible calibrations. To aid in probe placement, this system provides for good visual access and precise probe positioning. Due to the complexity of probe contact in a cryogenic vacuum environment, the LRRM method w/ load inductance compensation with its minimum number of required standards is currently considered the calibration technique of choice.

\section{Acknowledgments}

This work was performed at Sandia National Laboratories supported by the U. S. Department of Energy under contract \#DE-AC04-94AL85000. The authors would like to thank Terry Burcham and John E. Pence of Cascade Microtech, Inc. for providing their expertise in on-wafer calibration; Nick R. Brubaker of TRI Research, St. Paul, Minnesota for assistance in cryogenic design; Marc E. Sherwin, John C. Zolper, and Albert G. Baca of Sandia National Laboratories for providing the n-channel JFET, and Chris P. Tigges of Sandia National Laboratories for his critical review of this manuscript.

\section{References}

[1] J. Laskar and J. Kolodzey, "Cryogenic vacuum high frequency probe station," J. Vac. Sci. Technol. B 8(5), pp. 1161-1165, Sep/Oct 1990.

[2] H. Meschede, R. Reuter, J. Albers, J. Kraus, D. Peters, W. Brockerhoff, R.-J. Tegude, M. Bode, J. Schubert, and W. Zander, "On-Wafer Microwave Measurement Setup for Investigations on HEMT"s and High $\mathrm{T}_{\mathbf{c}}$ Superconductors at Cryogenic Temperatures Down to $20 \mathrm{~K}$," IEEE Trans. Microwave Theory Tech., vol. 40 , no. 12, pp. 2325-2331, Dec. 1992.

[3] T. Mizutani, and K. Maezawa, "Temperature Dependence of High-Frequency Performance of $\mathrm{Al}$ iaAs/InGaAs Pseudomorphic HEMT"s," ILEKE Electron Device Lett., vol. 13, no. 1, pp. 8-10, Jan. 1992.

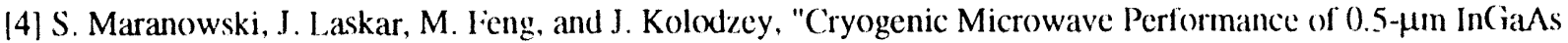
MESFET"s," ILEEE Electron Device Lett., vol. 13, no. 1, pp. 64-66, January 1992.

[5] R. B. Marks, "A Multiline Method of Network Analyzer Calibration," IEEEE Trans. Microwave Theory Tech., vol. 39, no. 7, pp. 1205-1215, July 1991.

[6] D. F. Williams, R. B. Marks, and A. Davidson, "Comparison of On-Wafer Calibrations," 38th ARIFT Conference Digest, December, 1991.

[7] A. Davidson, K. Jones, and E. Strid, "I.RM and LRRM Calibrations with Automatic Determination of Load inductance," 36th ARFTG Conference Digest, November, 1990.

[8] J. E. Pence, "Verification of LRM Calibrations with Load Inductance Compensation for (PPW Measurements on GaAs Substrates," 42th ARFTG Conference Digest, November, 1993.

[9] J. C. Zolper, M. E. Sherwin, A. G. Baca, R. J. Shul, A. J. Howard, D. J. Rieger, J. I'. Klem, and V. M. Hietala, "A Self-Aligned Zn-Gate JIET by Ion Implantation", Proceedings of 1993 International Semiconductor Device Research Symposium. pp. 295-298, Dec. 1-3, 1993. 


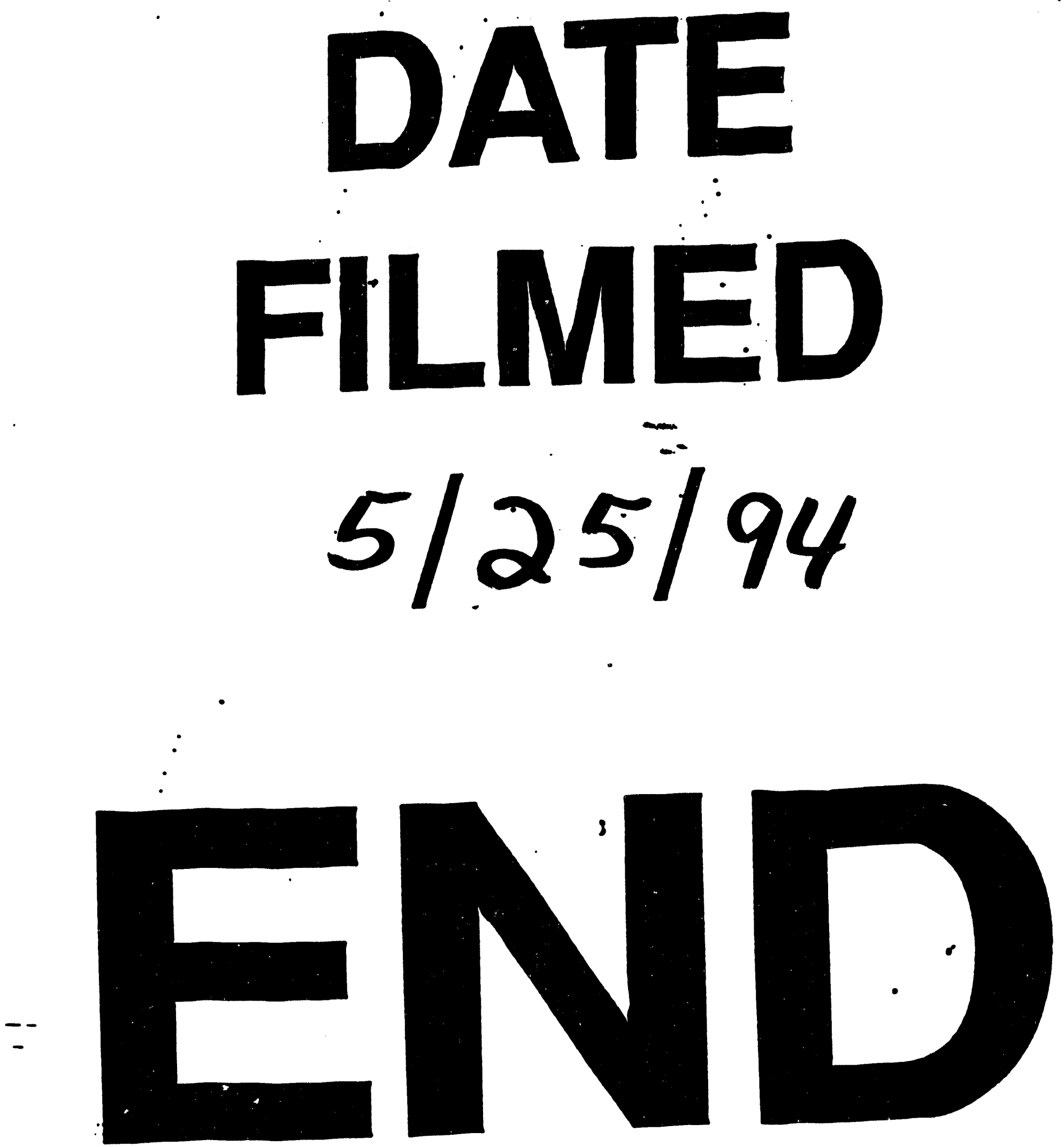

